\title{
Numerical Analysis of R/C Cylindrical Shell with Hoop Edge Beams under External Pressure
}

Takashi Hara

\begin{abstract}
Reinforced concrete $(\mathrm{R} / \mathrm{C})$ cylindrical shell with hoop edge beams was analyzed by using the nonlinear FEM. $R / C$ shell with free edges must be stiffened by the edge beam. From the numerical results of the previous papers, the minimum size of the edge beam was placed on both hoop edges under self weight as the beam having the maximum ratio of the strength to the weight. In this paper, three kinds of connecting position between $\mathrm{R} / \mathrm{C}$ shell and the edge beam were considered. One was the concentric connection of $\mathrm{R} / \mathrm{C}$ shell and the beam (Type C). The second one was the shell connected at the top of the beam (Type $L$ ). The third one was the shell connected with the bottom of the beam (Type $\mathrm{U}$ ). R/C shell was pin supported on the meridian and free on the hoop edges. Uniformly distributed pressure was applied to the model. From the numerical analyses, it was concluded that $T y p e ~ L$ was efficient.
\end{abstract}

Keywords - R/C shell, cylindrical shell, edge beam, ultimate strength, connection

\section{Introduction}

Reinforced Concrete (R/C) shell has been constructed to cover large public spaces and underground structures. R/C shell is originally a continuous structure and shows the large load bearing capacity. To apply these structures to such purposes, the structure is cut at any particular portion and loses their continuum properties. Therefore, edge beams must be placed to avoid the stress concentration and a local failure on the cutting edges. Fig. 1 shows the cylindrical shell under uniformly distributed pressure.

IASS recommendation [1] and ACI building code [2] recommend to place edge beam at free edges and the intersection of shells. However, the required dimension and the details of connection method between shell and edge beam are not clearly recommended. In the previous paper [3], the effects of the edge beams placed along the meridional edges were analyzed under self weight and also in [4] R/C shell with hoop edge beam under distributed load was analyzed. They were concluded that the connection method between $\mathrm{R} / \mathrm{C}$ shell and edge beam influenced the strength of $\mathrm{R} / \mathrm{C}$ shell subjected to the lateral pressure.

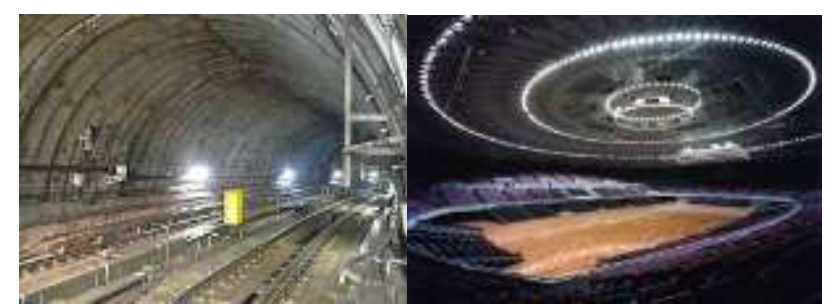

(a)Tunnel

(b) Underground Gymnasium

Fig.1 R/C shell under pressure
$\mathrm{R} / \mathrm{C}$ shell had 960x960 mm plan and the thickness was $10 \mathrm{~mm}$. RC shell was supported along the meridional edges and was subjected to the external pressure. As the edge beam, three kinds of rectangular beams, which had $2 \mathrm{~cm}$ width and $3.5 \mathrm{~cm}$ depth, were arranged. In the numerical analyses, the deformation and the stress distribution of the shell mentioned above were analyzed precisely.

\section{Numerical Model}

\section{A. Model Geometry}

Fig. 2 shows R/C shell model [5]. The size of R/C shell is small considering the future experimental analyses. The width and length of cylindrical shell are $960 \mathrm{~mm}$ and $960 \mathrm{~mm}$, respectively. The thickness of the shell is $10 \mathrm{~mm}$. Radius of the cylinder is $688 \mathrm{~mm}$. In the middle of the shell thickness, reinforcement mesh (diameter $0.75 \mathrm{~mm}$ ) with $5 \mathrm{~mm}$ openings is arranged. On both the hoop edges, edge beams were arranged. Figure shows the dimensions of R/C shell with the edge beam.

When the beam thickness was $20 \mathrm{~mm}, \mathrm{R} / \mathrm{C}$ shells with various beam depth were calculated [5] and the economical

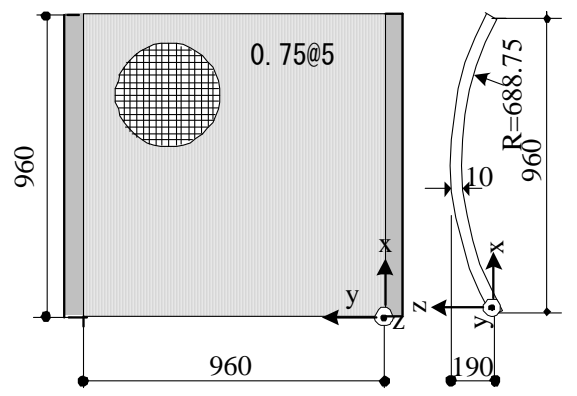

Figure 2 Geometric dimensions of R/C cylindrical shell (mm)

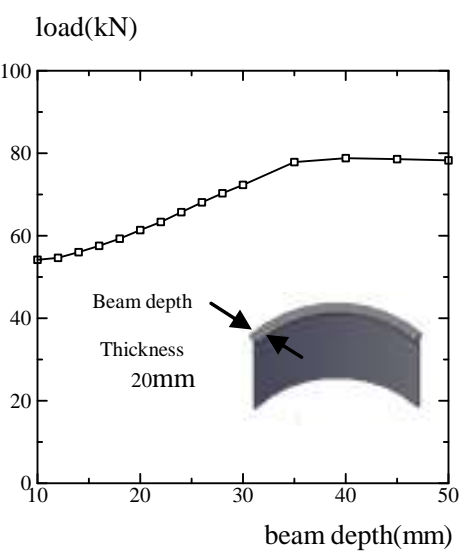

Figure3 Relation between the beam depth and the ultimate load [6] 
size of the edge beam was decided as $20 \mathrm{~mm}$ width and $35 \mathrm{~mm}$ depth considering the total weight of $\mathrm{R} / \mathrm{C}$ shell with edge beams (see Fig. 3). The stiffened R/C shell is pin supported along the meridional edges.

Three kinds of arrangements of the edge beam were considered. Fig. 4 shows the arrangements of the edge beam. In Type $\mathrm{C}$, the edge beam is connected to $\mathrm{R} / \mathrm{C}$ cylindrical shell at the gravity center. In Type L and Type U, the edge of $\mathrm{R} / \mathrm{C}$ shell is connected to the top and the bottom of the edge beam, respectively. The same reinforcements as $\mathrm{R} / \mathrm{C}$ shell were arranged both along inner and outer surfaces of the beam thickness. The cover of the micro concrete was $5 \mathrm{~mm}$.



(a) No rib

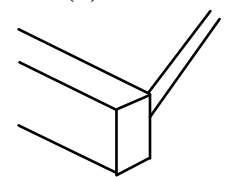

(c) L-type

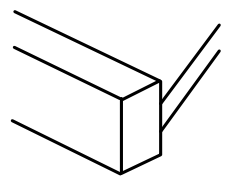

(b) C-type

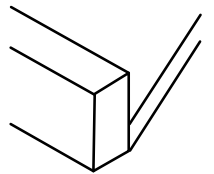

(d) U-type
Figure 4 Connection of edge beam

\section{B. Material Properties}

The model was assumed to construct by the mild steel and the micro concrete. Both the material parameters are shown in Table 1. Material properties were obtained from the material tests.

Table 1 Material properties of concrete and steel

\begin{tabular}{lr}
\hline \multicolumn{2}{c}{ Concrete } \\
\hline Compressive Strength $(\mathrm{MPa})$ & 38.2 \\
Tensile Strength(MPa) & 3.8 \\
Young's Modulus(GPa) & 23.6 \\
Poisson's Ratio & 0.20 \\
\hline \multicolumn{1}{c}{ Steel } \\
\hline Yield Stress(MPa) & 235 \\
Tensile Stress(MPa) & 449 \\
Young's Modulus(GPa) & 206 \\
Tangential Modulus(GPa)
\end{tabular}

\section{Numerical Model}

Fig. 5 shows the numerical models. Type $\mathrm{C}$ denotes the model with edge beams connected at the gravity center of the beams. Type $L$ and Type $U$ show the model with edge beams connected at the top and the bottom of the beam, respectively. Each model was divided into solid elements with 20 nodes.

The inelastic behavior of concrete possesses the recoverable strain components and irrecoverable strain components. Under tri-axial stress state, the yield function depends not only on the mean normal stress $I_{l}$ but also on the second deviatoric stress invariant $J_{2}[6,7]$.

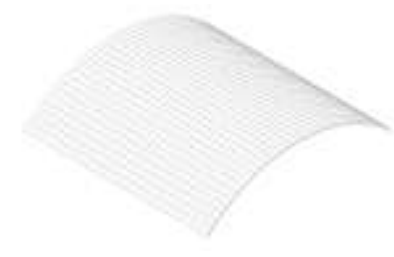

(a) no rib
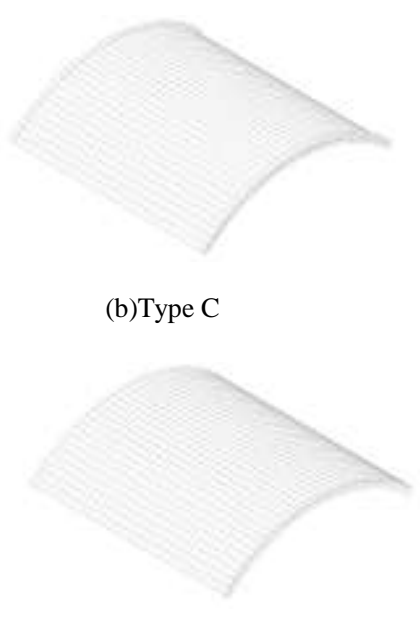

(c) Type U
(b)Type C

Figure 5 Numerical model

The yield condition of tri-axial compressive concrete is expressed by Drucker Prager criterion [6-9].

$$
f\left(I_{1}, J_{2}\right)=\sqrt{\beta\left(3 J_{2}\right)+\alpha I_{1}}=\sigma_{0}
$$

where $\alpha$ and $\beta$ are the constants. Also $\sigma_{0}$ is the equivalent stress.

Parameters adopted in the criterion are defined by the Kupfer's experiment [10]. It is assumed that the initial yield begins when the equivalent stress exceeds $0.3 f_{c}$ ( $f_{c}$ : compressive strength of concrete) [7]. Also, the crushing condition of concrete is described as a strain control phenomenon and the crushing condition is defined as like as the yield function (1).

The response of concrete in tension is modeled as a linear-elastic brittle material and maximum tensile stress criteria are employed. After cracking, to evaluate the stiffening of reinforced concrete, the stress reduction of the concrete normal to the cracked plane is assumed as an exponential degradation curve (see Fig.6).

$$
\sigma_{i}=f_{t}^{\prime} \exp \left(-\frac{\varepsilon_{i}-\varepsilon_{0}}{\gamma}\right) \quad \gamma=\frac{G_{f}-0.5 f_{t}^{\prime} \cdot \varepsilon_{0} \cdot l_{c}}{f_{t}^{\prime} \cdot l_{c}}
$$

where $f_{t}{ }^{\prime}$ is maximum tensile strength of concrete, $\gamma$ is the tension stiffing parameter, $\varepsilon_{0}$ is crack strain when the stress reaches $f_{t}^{\prime}$ from the initial status i.e., $f_{t}{ }^{\prime}=E_{0} \varepsilon_{0} . G_{f}$ is the fracture energy of concrete, $l_{c}$ is the cubic root of volume in Gaussian point. $\gamma=0.1$ is adopted in this paper due to the characteristics of normal concrete.

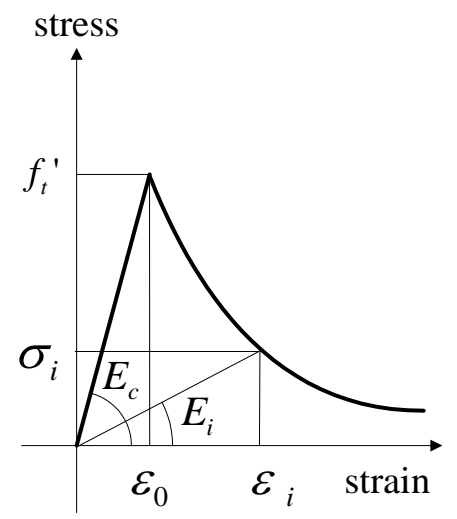

Figure 6 Stress strain in tension 
The reinforcing bars are considered as steel sheet. The bilinear idealization is adopted in order to model the elastoplastic stress strain relationship and both the tensile and the compressive states are governed by the same relationship [7].

\section{Numerical Results}

Fig. 7 shows the load - displacement relation for each connecting method between edge beam and R/C shell. The displacements are shown at the center on the surface of $\mathrm{R} / \mathrm{C}$ shell. The downward deformation is defined as the positive direction. The loading condition is an uniformly distributed pressure. The ordinate in the figure denotes the applied load $\left(\mathrm{N} / \mathrm{mm}^{2}\right)$. The legend "no rib" means the numerical result of $\mathrm{R} / \mathrm{C}$ shell without edge beams.

The edge beam improves 1.61 to 1.70 times the load carrying capacity of $\mathrm{R} / \mathrm{C}$ shell without hoop beams under an uniformly distributed pressure. R/C shell of Type L shows the largest stiffness and ultimate strength. The ultimate strength of $\mathrm{R} / \mathrm{C}$ shell with edge beams shows almost the same. However, R/C shell without edge beams shows almost a half of the ultimate strength of those with edge beams.

Pressure $\left(\mathrm{N} / \mathrm{mm}^{2}\right)$

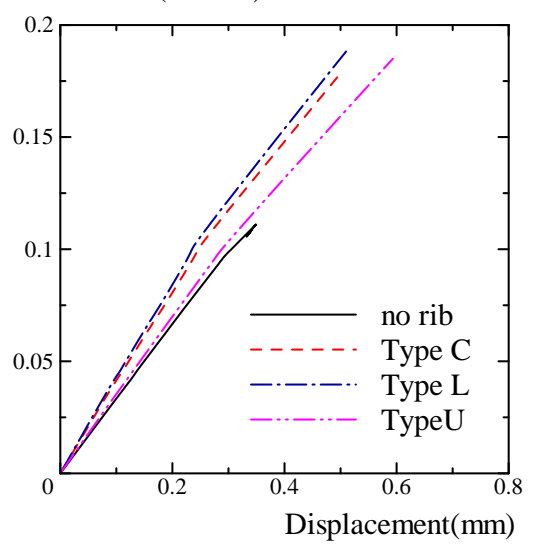

Figure 7 Load -displacement relation

Fig. 8(a) shows the deformation patterns of R/C shell without edge beams. R/C shell without edge beams shows the snap buckling on the meridian at a quarter of the shell width from the supports.

Figs. 8 (b) to $8(\mathrm{~d})$ show the deformations of R/C shell with edge beams along hoop edges. $\mathrm{R} / \mathrm{C}$ shell connected at the gravity center of the edge beam (Type C) and R/C shell connected at the top of the edge beam (Type L) show almost the same deformation pattern. The edge beams does not deform along the hoop direction. In case of $\mathrm{R} / \mathrm{C}$ shell connected at the bottom of the edge beam (Type U), R/C shell around the connection with the edge beam deforms and rotates along the hoop edges. Therefore, the load carrying capacity of Type $U$ was smaller than those of Type L and Type C. However, the local deformation amount of $\mathrm{R} / \mathrm{C}$ shell are almost the same.

Fig. 9(a) shows the crack pattern of R/C shell without edge beam. In the figure, a rectangle denotes a cracking at a integration point and a surface denotes cracking direction. (*) marks denote the crashing of a concrete. From the figure, cracks arise at $\mathrm{R} / \mathrm{C}$ shell corners. The crushing arises both meridional and hoop direction. Especially, crushes propagate along meridian.

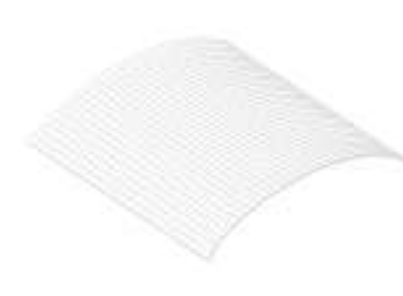

(a) no rib
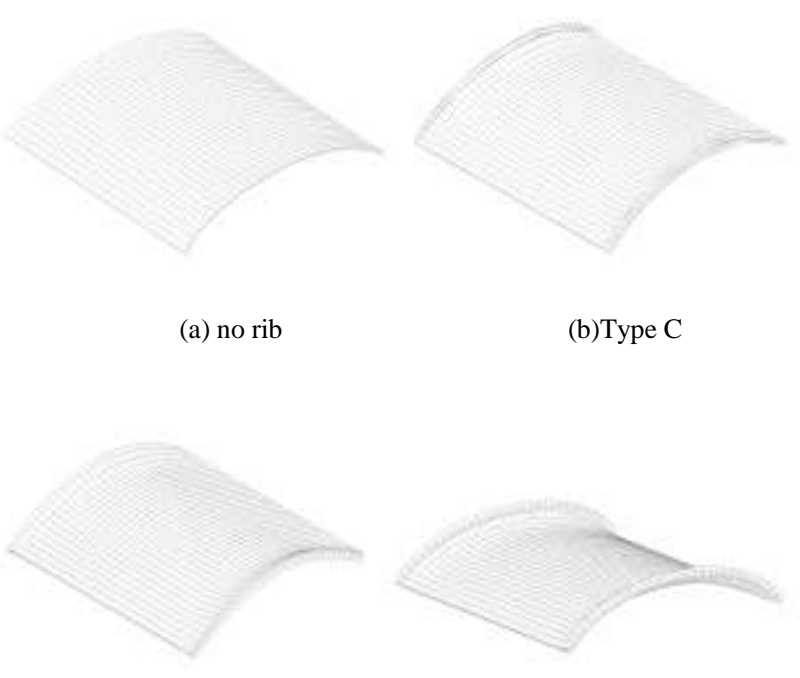

(c) Type L

(d)Type U

Figure 8 Deformation of the shell

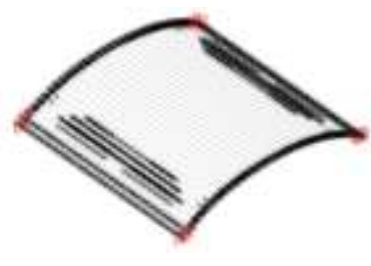

(a) no rib

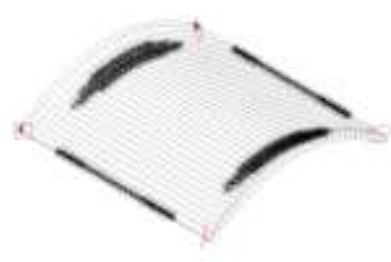

(c)Type L

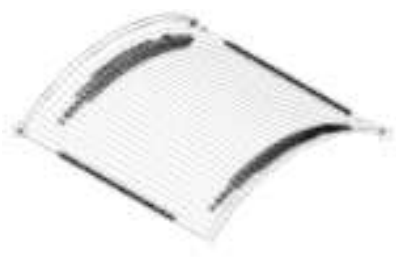

(b)Type C

(d)Type U

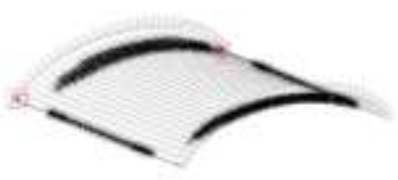

Figure 9 Cracks and Crushes on the Shell

Figs. 9(b) to 9(d) show the crack and crush pattern of $\mathrm{R} / \mathrm{C}$ shell with several types of edge beams. Cracks only occur at $\mathrm{R} / \mathrm{C}$ shell corners. Type $\mathrm{C}$ and Type $\mathrm{L}$ show almost the same crush patterns. Crushing is restricted along hoop direction. However, in case of Type U, crushes concentrate on $\mathrm{R} / \mathrm{C}$ portion near the hoop edges.

Fig. 10 shows the equivalent stresses in $\mathrm{R} / \mathrm{C}$ shell at each ultimate state. In case $\mathrm{R} / \mathrm{C}$ shell without edge beam, the stresses in all edges are large. However, the particular stress concentrations are not detected. The stress patterns of Type $\mathrm{C}$ and Type $\mathrm{L}$ show almost the same. However, in case of Type U, the hoop beams themselves show higher stress state than Type $\mathrm{C}$ and Type L. It is depend on the rotational deformation of the edge beam.

\section{Conclusions}

In this paper, $\mathrm{R} / \mathrm{C}$ cylindrical shell with edge beam on hoop free edges was analyzed by use of FEM. The minimum size of the edge beam was placed from the results of the 

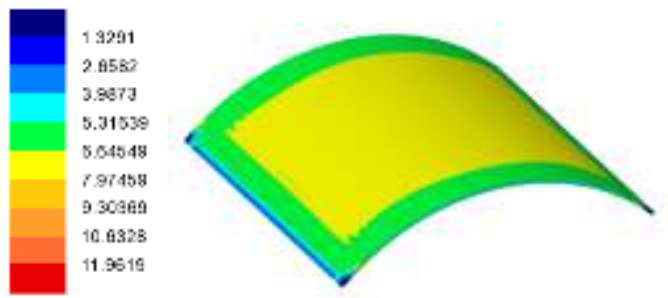

(a) no rib
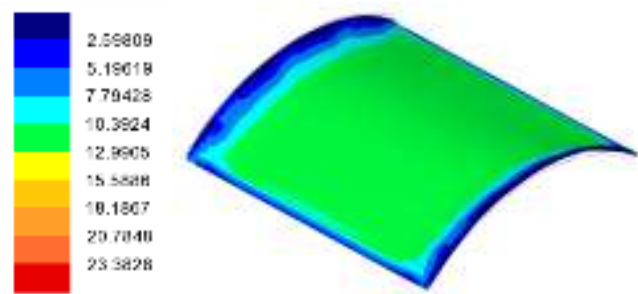

(b)Type C
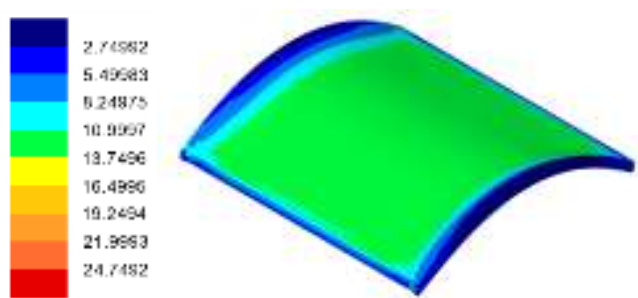

(c)Type L
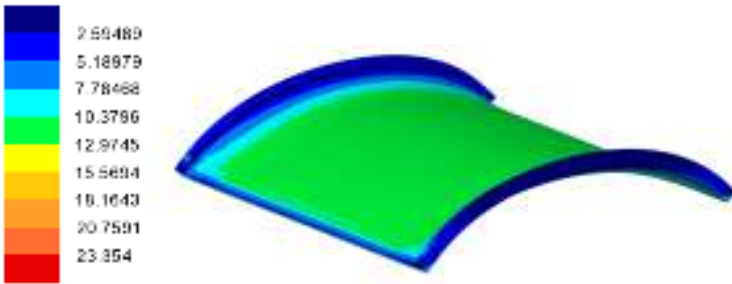

(d)Type U
(2)In case of $\mathrm{R} / \mathrm{C}$ shell connected at the bottom of the beam, the edge beam requires the greater stiffness than those with other connection method to prevent the edge beam failure.

(3)At all cases, the edge beams on the hoop edge improve 1.61 to 1.70 times the strength of $\mathrm{R} / \mathrm{C}$ shell without edge beam.

(4)The edge beam plays an important role to avoid R/C shell failure itself. The edge beam prevents the crack and crush propagations from the edge to inner portion of R/C shell.

\section{Acknowledgment}

This research work was done under the supports of Grants-in-Aid for Scientific Research, Japan Ministry of Education, Culture, Sports, Science and Technology (No. 26420573).

\section{References}

[1] IASS Working Group 5, IASS Recommendation for Reinforced Concrete Shell and Folded Plates, IASS, 1979

[2] ACI Committee318, Building Code Requirements for Structural Concrete 318-14, American Concrete Institute, 2011

[3] T. Hara, Structural Behavior of R/C Shell considering the Position of Edge Beam, Proceedings of ISEC08 pp299-304 2015

[4] T. Hara, Numerical analysis of R/C cylindrical shell with hoop edge beam, Proceedings of SCESCM 2016, 8p, 2016

[5] T. Hara, Numerical Evaluation of the Effects of Hoop Edge Beams Attached to the Cylindrical R/C Shell, Proceedings of ISEC06, pp 1053-1058, 2011

[6] E. Hinton and D.R.J. Owen, Finite Element Software for Plates and Shells, Pineridge Press, 1984

[7] E. Hinton, Numerical methods and software for dynamic analysis of plates and shells, Pineridge press Swansea U.K. 1988

[8] T. Hara, Dynamic analysis of R/C cooling tower shells under earthquake loading, 5th International Symposium on Natural-Draught Cooling Towers, 283-291, 2004.

[9] T. Hara and M.N.S. Hadi, Behaviour of high strength concrete columns under cccentric loading. Proceedings of the Tenth International Conference on Civil, Structural and Environmental Engineering Computing p16, 2005

[10] H. Kupfer and K.H. Hilsdorf, Behavior of concrete under biaxial stress, ACI Journal, 66, 656-666. 1969

Fig. 9 Equivalent stresses in the shell (unit: $\mathrm{N} / \mathrm{mm}^{2}$ )

previous paper. In numerical analysis, the different arrangements of the edge beam were considered. The gravity center, the top and the bottom of the edge beam are connected to $\mathrm{R} / \mathrm{C}$ cylindrical shell. Then, the deformation and the ultimate strength as well as the stress states were investigated. From the numerical results, following conclusions are obtained.

(1) The arrangement of the edge beam influences the strength of R/C shell with edge beam. Edge beam connected at the top of the beam is better than that connected at the bottom of the beam. Edge beam connected at the gravity center shows almost the same performance as that of Type $\mathrm{L}$.
About Author:

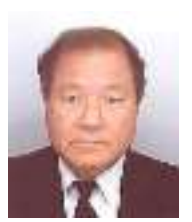

Takashi Hara, Professor, Dr.-Eng. PE-jp National Institute of Technology,

Tokuyama College

Graduate from Ehime University, Japan

Dr. of Eng. Toyohashi University of

Technology, Japan

APEC Structural Engineer 